\title{
Effect of aging on carotid artery stiffness and baroreflex sensitivity during head-out water immersion in man
}

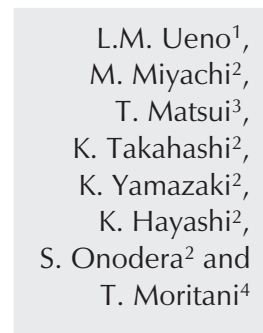

\author{
${ }^{1}$ Instituto do Coração, Faculdade de Medicina, Universidade de São Paulo, São Paulo, \\ SP, Brasil \\ ${ }^{2}$ Department of Health and Sports Sciences, Kawasaki University of Medical Welfare, \\ Okayama, Japan \\ ${ }^{3}$ Department of Health Welfare and Human Performance, KIBI International University, \\ Okayama, Japan \\ ${ }^{4}$ Laboratory of Applied Physiology, Kyoto University, Graduate School of Human and \\ Environmental Studies, Kyoto, Japan
}

\section{Correspondence \\ L.M. Ueno \\ Unidade de Reabilitação \\ Cardiovascular e Fisiologia \\ do Exercício, InCor \\ Av. Dr. Enéas C. Aguiar, 44 \\ 05403-000 São Paulo, SP \\ Brasil \\ Fax: +55-11-3069-5043 \\ E-mail: lindabrz@hotmail.com \\ Research supported in part by the Japanese Ministry of Education, \\ Science, Sports and Culture \\ Grants-in-Aid for Scientific \\ Research \#1148011 and \\ \#14208005.}

Publication supported by FAPESP. .....................

Received April 16, 2004

Accepted January 20, 2005

\begin{abstract}
To examine the possible age-related blood pressure (BP) deregulation in response to central hypervolemia, we measured spontaneous baroreflex sensitivity (SBRS), carotid arterial compliance (CC), and R-R interval coefficient of variation (RRICV) during basal and thermoneutral resting head-out-of-water immersion (HOWI) in 7 young $(\mathrm{YG}=$ $24.0 \pm 0.8$ years $)$ and 6 middle-aged/older $(\mathrm{OL}=59.3 \pm 1.3$ years $)$ healthy men. Compared with basal conditions ( $\mathrm{YG}=19.6 \pm 4.0 \mathrm{vs} \mathrm{OL}$ $=6.1 \pm 1.5 \mathrm{~ms} / \mathrm{mmHg}, \mathrm{P}<0.05)$, SBRS remained higher in $\mathrm{YG}$ than OL during rest $\mathrm{HOWI}(\mathrm{YG}=23.6 \pm 6.6 v \mathrm{~s} \mathrm{OL}=9.3 \pm 2.1 \mathrm{~ms} / \mathrm{mmHg}$, $\mathrm{P}<0.05)$. The RRICV was significantly different between groups $(\mathrm{YG}=6.5 \pm 1.4 v s \mathrm{OL}=2.8 \pm 0.4 \%, \mathrm{P}<0.05)$ under HOWI. The OL group had no increase in CC, but a significant increase in systolic BP (basal $=115.3 \pm 4.4 v s$ water $=129.3 \pm 5.3 \mathrm{mmHg}, \mathrm{P}<0.05)$ under HOWI. In contrast, the YG group had a significant increase in $\mathrm{CC}$ (basal $=0.16 \pm 0.01 v s$ water $=0.17 \pm 0.02 \mathrm{~mm}^{2} / \mathrm{mmHg}, \mathrm{P}<0.05$ ) with no changes in systolic BP. SBRS was positively related to $\mathrm{CC}(\mathrm{r}=$ $0.58, \mathrm{P}<0.05$ for basal $v s \mathrm{r}=0.62, \mathrm{P}<0.05$ for water). Our data suggest that age-related vagal dysfunction and reduced $\mathrm{CC}$ may be associated with SBRS differences between YG and OL groups, and with BP elevation during HOWI in healthy older men.
\end{abstract}

Key words

- Aging

- Baroreflex sensitivity

- Carotid compliance

- Water immersion

- Hypertension

- Vascular stiffness

\section{Introduction}

Orthostatic hypotension is prevalent with aging (1) and a proposed underlying mechanism is associated with impaired arterial baroreflex sensitivity (BRS; 2,3). It has been reported that in hypovolemic stress induced by head-up-tilt, the fluid shifts from the upper to the lower part of the body, unloading cardiopulmonary and arterial baroreceptors. In contrast, head-out-of-water immersion (HOWI) results in a significant increase in cardiac filling accompanied by loading of cardiopulmonary and arterial baroreceptors (4). Arterial baroreceptors are sensory nerve endings that innervate large arteries (carotid sinuses and aortic arch) and appear to contribute importantly to the regulation of blood 
pressure (BP) by the withdrawal of cardiac vagal tone (the immediate increase in heart rate (HR) determined by the acceleration of the electrocardiographic (ECG) R-R interval) during orthostatic challenge (5).

Age-related changes seem to provoke autonomic changes with impairment of vagal baroreflex and increases of baseline muscle sympathetic nerve activity (2). Shi et al. (6) demonstrated that age-related cardiac vagal dysfunction is associated with an attenuated response of BP regulation during hypovolemic stress. Their study showed that the elderly experienced orthostatic hypotension at the onset of orthostatic challenge because of a diminished HR response, but the increased vasoconstriction helped maintain their BP during a hypovolemic stress.

It has long been believed that aging leads to progressive structural and functional changes within the arterial walls, which are associated with increased vascular stiffness (7). In association with structural alterations, the elastic properties of the carotid arterial wall are reduced, blunting the baroreceptor response to increases in BP (8). Studies have revealed that the reduced carotid artery compliance $(9,10)$ plays an important role in the age-associated decrease in cardiac BRS. On the other hand, studies $(11,12)$ using hypovolemic circulatory stress have not detected changes in cardiovascular reflex responses with aging. Thus, the inconclusive findings concerning baroreflex responsiveness in young and older men, as well as its physiological consequences, provide a compelling rationale for the study of hemodynamic changes associated with BP regulation with advancing age.

The primary goal of the present study was to investigate age-related changes in cardiac autonomic control and elastic properties of the carotid artery related to BP regulation during resting hemodynamic stress. We used water immersion to load arterial and cardiopulmonary baroreceptors and hypothesized that: i) BP deregulation is prevalent in older adults and an underlying mechanism may be the result of impaired BRS, and ii) age-related vagal dysfunction and elastic properties of the carotid artery could be related to BP changes and BRS responses during hemodynamic stress.

\section{Material and Methods}

\section{Subjects}

Thirteen healthy males, 7 young (YG, 24 \pm 0.8 years) and 6 middle-aged/older men (OL, $59.3 \pm 1.3$ years), volunteered for the study. All signed an informed consent form released prior to participation. The experiments were carried out with the approval of the Ethics Committee of Kyoto University, Graduate School of Human and Environmental Studies. The subjects studied are normotensive (BP $<140 / 90 \mathrm{mmHg}$ ) with no evidence of renal or cardiovascular disease as indicated on the basis of medical history and of a resting electrocardiogram.

\section{Experimental design}

All of the experimental procedures were performed in two randomized sessions (resting basal conditions and during resting HOWI) on separate days at the same time each day. The following randomized measurements were made: anthropometric parameters, carotid artery diameter (CD), echocardiography measures, beat-to-beat HR, and BP. All measurements were made with the subject in the upright-seated position.

\section{Experimental procedures}

All measurements were made with the subjects sitting on a chair under resting basal conditions (air temperature of $27^{\circ} \mathrm{C}$ ) and in a similar position during rest thermoneutral water immersion. An adjustable chair was placed in the swimming pool to adjust the water to heart level in all subjects evaluated. The subject, wearing only swim shorts, was 
instrumented with cuffs around the left upper arm and right finger for the determination of brachial and peripheral arterial BP, respectively. Simultaneously, a beat-to-beat HR signal was recorded using a bipolar lead (CM5 lead). The noninvasive peripheral BP wave was recorded using an automatic sphygmomanometer (Finapress 2300, Ohmeda, Englewood, CO, USA) connected to a finger cuff containing a plethysmographic transducer. The noninvasive beat-to-beat BP recording device was fitted to the middle finger of the hand. The arm was placed at the level of the heart and adjusted for similar brachial BP values in all subjects under basal conditions and during rest HOWI. Then, the analog output of the ECG (with a band pass filter between 0.5 and $100 \mathrm{~Hz}$ ) and $\mathrm{BP}$ signals were digitized via a 13-bit analog-todigital converter (Trans Era Corporation, South Orem, UT, USA) at a sampling rate of $1 \mathrm{kHz}$. The beat-to-beat ECG and BP signals collected under basal conditions and during rest HOWI were stored on a computer hard disk for later analysis. To analyze spontaneous BRS (SBRS) and HR variability (HRV) the beat-to-beat ECG and BP signals were collected for $300 \mathrm{~s}$.

Our beat-to-beat ECG and BP data collection procedures have been described in detail $(13,14)$. The standard time domain analysis of HRV was performed by calculating the beat-to-beat ECG R-R interval coefficient of variation $[$ RRICV $=(\mathrm{R}-\mathrm{R}$ interval standard deviation $\times 100) /$ mean R-R interval]. In addition, the systolic (SBP) and diastolic blood pressure (DBP) was measured at the 5th and 10th min in the left brachial artery with a standard sphygmomanometer. Arterial pulse pressure (PP) was calculated from arterial SBP minus DBP, and mean arterial blood pressure (MBP) was calculated from DBP + 1/3 PP.

\section{Left ventricular vessel size}

Subjects were studied under quiet resting basal conditions while they were sitting on a chair and in a similar position during rest HOWI. Our procedures to measure left ventricular size have been described in detail elsewhere. Briefly, left ventricular enddiastolic diameter (LVEDD) and left ventricular end-systolic ascending aortic diameter (LVESD) were measured by M-mode echocardiography with a model SSD 870 apparatus (Aloka, Tokyo, Japan) with the 2.5-MHz sector probe as previously reported (15). LVEDD and LVESD were measured during end respiration as an average of measurements from $3 \mathrm{M}$-mode pictures obtained from parasternal long axis views. All measurements were performed in a blind fashion and analyzed by the same investigator. Stroke volume (SV) was derived from measurements of LVEDD minus LVESD volumes. Cardiac output $(\mathrm{CO})$ and total peripheral resistance were calculated from $\mathrm{HR}$ x SV and $\mathrm{MBP} / \mathrm{CO}$, respectively, using brachial MBP and HR values obtained before the measurements of M-mode echocardiography, as described previously (16).

\section{Carotid artery measurements}

Subjects were studied in a sitting position under resting basal conditions and during rest HOWI. Common CD was measured from the images derived from an ultrasound machine (Shimadzu SSD 350, Tokyo, Japan) equipped with a high-resolution linear array transducer $(7.5 \mathrm{MHz})$ as previously described by Miyachi et al. (17). A longitudinal image of the cephalic portion of the common carotid artery was acquired 1 to 2 $\mathrm{cm}$ proximal to the carotid bulb, with the transducer placed at a $90^{\circ}$ angle to the vessel so that near and far wall interfaces were clearly discernible. These images were recorded using a VHS videocassette recorder and analyzed with computerized image analysis software (NIH Image). The same investigator who was blind to the group of the subjects performed all image analysis. Meas- 
urements of maximal (systolic) and minimal (diastolic) lumen diameters from the media adventitia border of the near wall to the intima-lumen interface of the far wall were made for analysis. The $\triangle \mathrm{CD}$ was calculated using the difference between systolic $\left(\mathrm{CD}_{\text {sys }}\right)$ minus diastolic $\left(\mathrm{CD}_{\mathrm{dia}}\right) \mathrm{CD}$. For the determination of arterial compliance under basal conditions and during rest HOWI, we used the combination of common $\mathrm{CD}$ with peripheral BP measurements obtained under basal conditions and during rest HOWI, respectively, using the following equation previously described (18):

Arterial compliance $=[(\mathrm{CD} 1-\mathrm{CD} 0) / \mathrm{CD} 0] /$ $[2(\mathrm{P} 1-\mathrm{P} 0)] \times \pi \times(\mathrm{CD} 0)^{2}$

where arterial compliance is reported in $\mathrm{mm}^{2} /$ $\mathrm{mmHg} ; \mathrm{CD} 1=$ maximal $\mathrm{CD}(\mathrm{mm})$; $\mathrm{CD} 0=$ minimal $\mathrm{CD}(\mathrm{mm}) ; \mathrm{P} 1=$ highest $\mathrm{BP}$ $(\mathrm{mmHg}) ; \mathrm{P} 0=$ lowest $\mathrm{BP}(\mathrm{mmHg})$.

\section{Spontaneous baroreflex sensitivity}

The spontaneous baroreflex modulation

Table 1. Cardiovascular parameters at rest during basal conditions and during headout water immersion of young and older subjects.

\begin{tabular}{|c|c|c|c|c|}
\hline & \multicolumn{2}{|c|}{ Young group } & \multicolumn{2}{|c|}{ Older group } \\
\hline & Basal & Water & Basal & Water \\
\hline Heart rate (bpm) & $58.4 \pm 3.5$ & $57.1 \pm 3.1$ & $62.9 \pm 4.6$ & $63.4 \pm 5.6$ \\
\hline RRICV (\%) & $4.8 \pm 0.8$ & $6.5 \pm 1.4$ & $2.3 \pm 0.4$ & $2.8 \pm 0.4^{\ddagger}$ \\
\hline Systolic BP (mmHg) & $106.9 \pm 2.5$ & $105.9 \pm 3.6$ & $115.3 \pm 4.4^{*}$ & $129.3 \pm 5.3^{\ddagger}$ \\
\hline Diastolic BP (mmHg) & $63.7 \pm 2.4$ & $58.4 \pm 2.6$ & $70.5 \pm 4.5$ & $72.0 \pm 5.3^{\ddagger}$ \\
\hline Mean BP (mmHg) & $78.0 \pm 2.2$ & $74.2 \pm 2.1$ & $85.7 \pm 3.8$ & $91.0 \pm 4.6^{\ddagger}$ \\
\hline Pulse pressure $(\mathrm{mmHg})$ & $43.1 \pm 2.1$ & $47.4 \pm 4.5$ & $44.8 \pm 5.0$ & $57.3 \pm 5.3^{*}$ \\
\hline LVESD (mm) & $3.1 \pm 0.1$ & $3.1 \pm 0.2$ & $3.2 \pm 0.2$ & $3.2 \pm 0.2$ \\
\hline LVEDD (mm) & $4.7 \pm 0.1$ & $4.9 \pm 0.2$ & $4.7 \pm 0.2$ & $4.9 \pm 0.1$ \\
\hline Cardiac output (I/min) & $4.5 \pm 0.2$ & $5.2 \pm 1.3^{*}$ & $4.6 \pm 0.6$ & $5.5 \pm 1.1^{*}$ \\
\hline Stroke volume (ml) & $80.3 \pm 7.5$ & $94.7 \pm 3.7^{*}$ & $72.7 \pm 7.5$ & $85.7 \pm 4.6^{*}$ \\
\hline TPR (mmHg per I/min) & $17.3 \pm 0.9$ & $14.4 \pm 2.2$ & $20.4 \pm 3$ & $17.8 \pm 2$ \\
\hline
\end{tabular}

Data are reported as means \pm SEM. Young group ( $24 \pm 0.8$ years, $N=7)$; older group $(59.3 \pm 1.3$ years, $N=6) ; R R I C V=E C G R-R$ interval coefficient of variation; $B P=$ blood pressure; $L V E S D=$ left ventricular end-systolic diameter; $L V E D D=$ left ventricular end-diastolic diameter; TPR = total peripheral resistance.

${ }^{*} \mathrm{P}<0.05$ basal vs water (two-way ANOVA). of HR was assessed using the sequence method. Details of this analysis have been previously described (19). Briefly, sequences of three or more consecutive beats, characterized by either a progressive rise in SBP and lengthening of $\mathrm{R}-\mathrm{R}$ interval $(+\mathrm{RR} /+\mathrm{SBP}$ sequences) or by a progressive decrease in SBP and shortening of the ECG R-R interval (-RR/-SBP sequences) with a correlation higher than 0.80 were identified. A linear regression was applied to each sequence and the mean individual slope of the significant SBP/R-R interval relationship obtained by averaging all slopes computed within the test period was calculated and taken as a measure of the SBRS.

\section{Statistical analysis}

Data are reported as means \pm SEM. The unpaired Student $t$-test was used to assess statistical differences in anthropometric characteristics. Two-way analysis of variance for repeated measures was used to analyze differences between conditions (basal condition; water) and groups (YG; OL). When a significant effect was found, the Scheffé test for multiple comparisons was applied for condition and group. An alpha level of 0.05 was used to determine statistical significance. The relationships between SBRS and CD measured during rest HOWI were determined by linear regression analysis. The correlation coefficient (r) was calculated for the product-moment equation. All calculations were performed using the Statistica statistical program (version 5.0 for windows; StatSoft Inc., Tulsa, OK, USA).

\section{Results}

There was a significant difference in age between the YG and OL groups $(24.0 \pm 0.8$ vs $59.3 \pm 1.3$ years, $\mathrm{P}<0.01$ ), but no significant difference in height $(171.5 \pm 1.4 \mathrm{vs}$ $169.0 \pm 2.9 \mathrm{~cm}, \mathrm{P}>0.05)$, weight $(71.1 \pm 4.6$ vs $68.9 \pm 4.1 \mathrm{~kg}, \mathrm{P}>0.05$ ), or body fat 
percentage $(22.0 \pm 3.0$ vs $20.6 \pm 1.6 \%, \mathrm{P}>$ $0.05)$.

\section{Cardiovascular responses}

The cardiovascular responses obtained for the two groups under the two conditions are shown in Table 1. No significant differences were detected in HR, LVESD, or LVEDD between groups between the basal condition and resting HOWI. There were no differences in RRICV between groups under basal conditions, but RRICV was significantly different between the YG and OL groups during resting HOWI. The SV and $\mathrm{CO}$ were significantly increased while total peripheral resistance was slightly decreased in both groups during rest HOWI compared with basal conditions, with no significant differences between groups. The YG group showed no increase in resting SBP or PP while the OL group showed a significant increase in SBP and PP during rest HOWI. There was a significant increase in SBP between groups during rest HOWI. The $\mathrm{DBP}$ and $\mathrm{MBP}$ in the YG group showed a slight decrease in response to resting HOWI, while the OL group showed a slight increase. We found a significant difference in DBP and MBP between groups during rest HOWI.

\section{Spontaneous baroreflex sensitivity}

The SBRS group data, CD and carotid artery compliance for both groups under the two conditions are shown in Table 2. SBRS was significant higher in the $\mathrm{YG}$ than in the OL group under basal conditions. Upon resting HOWI, the SBRS was significantly different between the YG and OL groups.

\section{Carotid artery diameter and compliance}

Under basal conditions, the $\mathrm{CD}_{\text {dia }}$ was greater while the $\Delta \mathrm{CD}$ was smaller in the $\mathrm{OL}$ group compared with the YG group. YG subjects had significant increases in $\mathrm{CD}_{\text {dia }}$ and $\mathrm{CD}_{\text {sys }}$ in response to resting HOWI, leading to a significant difference in $\triangle \mathrm{CD}$ compared with the OL group. On the other hand, OL individuals showed no significant changes in $\mathrm{CD}_{\text {dia }}$ and $\mathrm{CD}_{\text {sys }}$ diameters in response to resting HOWI. Arterial compliance was significantly higher in the YG than in the OL group under basal conditions and was consistently higher in the YG group during rest HOWI.

The relation between SBRS and elastic

Table 2. Spontaneous baroreflex sensitivity, carotid artery diameters, carotid arterial compliance during basal conditions and during head-out water immersion of young and older groups at rest are summarized.

\begin{tabular}{|c|c|c|c|c|}
\hline & \multicolumn{2}{|c|}{ Young group } & \multicolumn{2}{|c|}{ Older group } \\
\hline & Basal & Water & Basal & Water \\
\hline SBRS $(\mathrm{ms} / \mathrm{mmHg})$ & $19.60 \pm 4.5^{+}$ & $23.60 \pm 6.6$ & $6.10 \pm 1.5$ & $9.30 \pm 2.1^{\ddagger}$ \\
\hline $\mathrm{CD}_{\text {sys }}(\mathrm{mm})$ & $6.64 \pm 0.2$ & $7.16 \pm 0.1^{*}$ & $7.09 \pm 0.2$ & $7.21 \pm 0.3$ \\
\hline$C D_{\text {dia }}(\mathrm{mm})$ & $5.95 \pm 0.2^{+}$ & $6.41 \pm 0.1^{*}$ & $6.63 \pm 0.2$ & $6.76 \pm 0.2$ \\
\hline$\Delta \mathrm{CD}(\mathrm{mm})$ & $0.69 \pm 0.1^{+}$ & $0.75 \pm 0.1$ & $0.46 \pm 0.1$ & $0.46 \pm 0.1^{\ddagger}$ \\
\hline Compliance $\left(\mathrm{mm}^{2} / \mathrm{mmHg}\right)$ & $0.16 \pm 0.01^{+}$ & $0.17 \pm 0.02$ & $0.12 \pm 0.02$ & $0.10 \pm 0.02^{\ddagger}$ \\
\hline
\end{tabular}

Data are reported as means \pm SEM. Young group ( $24 \pm 0.8$ years, $N=7)$; older group $(59.3 \pm 1.3$ years, $N=6)$; SBRS = spontaneous baroreflex sensitivity; $C D_{\text {dia }}=$ diastolic carotid artery diameter; $C_{\text {sys }}=$ systolic carotid artery diameter; $\triangle C D=$ difference between $\mathrm{CD}_{\text {sys }}$ and $C \mathrm{CD}_{\text {dia. }}$.

${ }^{*} \mathrm{P}<0.05$ land $v s$ water; ${ }^{+} \mathrm{P}<0.05$ young $v s$ older during basal conditions; ${ }^{\ddagger} \mathrm{P}<0.05$ young vs older in water (two-way ANOVA).

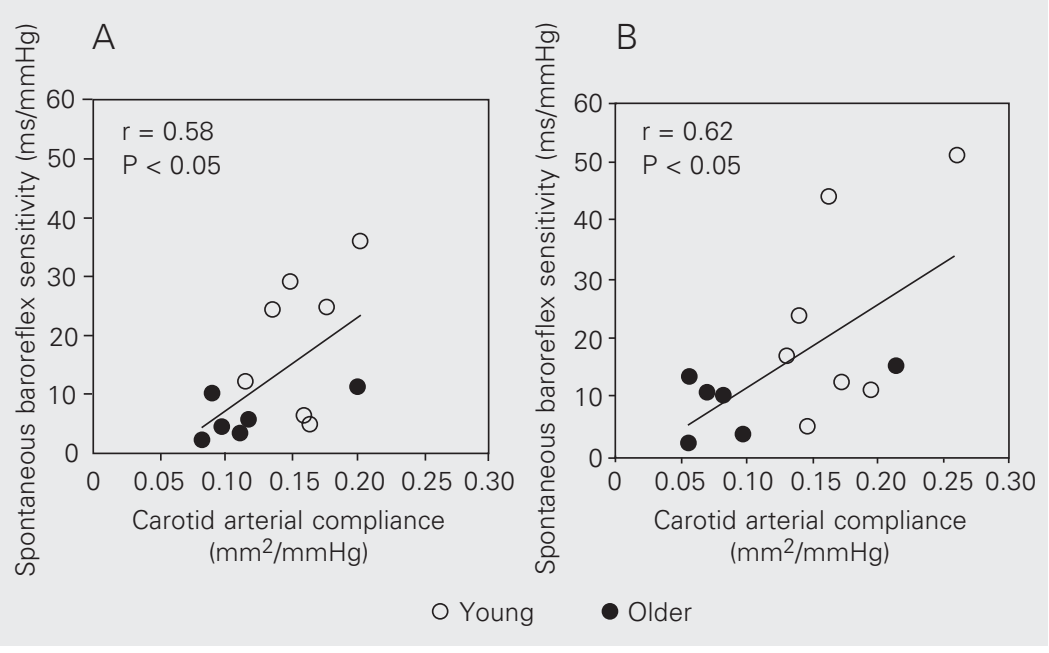

Figure 1. Scatter plots of spontaneous baroreflex sensitivity and carotid arterial compliance in all subjects during basal conditions (A), and during rest head-out water immersion (B). Correlation coefficients were determined by the method of Pearson. 
properties of the carotid artery was determined in all subjects under basal conditions and during rest hypervolemic circulatory stress (Figure 1). BRS was positively related to carotid arterial compliance $(\mathrm{r}=0.58, \mathrm{P}<$ $0.05)$ under basal conditions and a significant association also was present during rest HOWI $(r=0.62, \mathrm{P}<0.05)$.

\section{Discussion}

The goal of this study was to investigate age-related changes in cardiac autonomic control and elastic properties of the carotid artery related to BRS and BP regulation during resting hemodynamic stress. The new findings of this study are that the age-related vagal dysfunction and the elastic properties of the carotid artery may be related to SBRS differences between YG and OL groups, as was also the case for BP elevation during HOWI in healthy older men.

During rest HOWI, the RRICV, a measure of HRV, was significantly higher in the YG group, indicating a greater reflex action shifting the cardiovascular autonomic modulation toward the prevalence of parasympathetic activity. On the other hand, BP was significantly elevated in OL subjects with a lack of buffering vagal autonomic modulation during rest HOWI. These findings agree with previous studies suggesting that age-related vagal deficiencies may contribute to BP deregulation (6), which would reduce neural transduction of stretch into vagal outflow (associated with central autonomic integration, vagal outflow and sinoatrial node responsiveness) and blunt baroreflex responses (20).

In the present study, the SBRS was significantly higher in the YG than in the OL group under basal conditions. Upon resting HOWI, the SBRS was significantly different between OL and YG groups. Reduced BRS is associated with potentially adverse changes in BP control including an increase in arterial BP variability (21-24). On the other hand, HOWI is a powerful stressor used to assess autonomic nervous modulation as it relates to BP control. In the present study, our HOWI procedures stimulated arterial baroreceptors because PP and RRICV increased in the OL and YG groups, respectively. Since SBRS is based on analysis of spontaneous BP and HR fluctuations allowing us to assess the cardiac $\mathrm{BRS}$ as it operates in response to BP variations, in the present study, we chose the SBRS technique for analysis of cardiac BRS during rest HOWI.

It is well documented that a complex interaction exists between cardiac baroreflexes and arterial baroreflexes (25). Shi et al. (26) reported that an increase in central venous pressure due to lower body positive pressure (LBPP) or volume expansion diminished the carotid BRS. Potts et al. (27) reported that the baroreflex gain in HR was decreased by LBPP but was not affected by volume expansion in humans. For instance, one could predict that SBRS would be reduced during rest HOWI due to the increased firing of the cardiopulmonary and arterial baroreceptors, as seen in LBPP experiments. The discrepancy between the present and previous results using LBPP in YG groups may be due to the activation of intramuscular mechanoreceptors during LBPP, which has been reported to modulate the sympathetic nervous system (28).

It has been reported that leg venous compliance may have important implications for arterial BP regulation during orthostatic stress in men (29). A previous study (12) reported that the reduced cardiovascular reflex response found in the elderly during orthostatic stress seems to be caused by a reduced capacitance in the legs with age and a concomitantly smaller central hypovolemic stimulus rather than a reduced efficiency of the reflex response. In the present study, to avoid the influence of peripheral venous compliance on central blood volume, we used the sitting position during all measurements. Our results showed that both the YG and OL groups demonstrated an increase in 
SV to a similar extent during rest HOWI. Furthermore, the SV and CO increased in both groups without significant differences between them. Thus, our interventional stimulus using rest HOWI during the sitting position might have increased central blood volume in YG, as well as in OL subjects and loading baroreceptors to a similar extent.

Analysis of static measures of carotid hemodynamic indicated that $\mathrm{CD}_{\text {dia }}$ was greater in the OL compared with the YG group values at basal conditions. Also, the OL group showed a smaller $\triangle \mathrm{CD}$ during the cardiac cycle reflecting the loss of arterial wall distensibility in older adults. These changes between YG and OL are consistent with findings of previous studies showing the main modifications of the physical properties of large arteries in human vascular aging: an increase in arterial diameter (30) and a decreased distensibility (9). Despite increased $\mathrm{CD}_{\text {dia }}$ at baseline, OL subjects showed no changes in carotid diameters with resting HOWI, but a significant increase in peripheral SBP and PP during HOWI. On the other hand, the YG group had a significant increase in $\mathrm{CD}_{\text {dia }}$ and $\mathrm{CD}_{\text {sys }}$ diameters and peripheral MBP decreased by $4 \mathrm{mmHg}$. During rest HOWI, the MBP in the OL group increased by $5 \mathrm{mmHg}$ as compared to basal conditions. We found significant differences in MBP and DBP during resting HOWI between groups. Previous study (31) showed that transmural arterial pressure was linearly related to changes in carotid diameter. In patients after endarterectomy, those with increased carotid sinus diameter had greater carotid sinus nerve activity and lower postoperative BP (32). Thus, in the present study, the significant increase in carotid diameters in YG group during resting hypervolemic stress, may contribute to maintain stable the BP. On the other hand, the absence of changes in carotid diameters in OL group may reflect the large arterial rigidity with advancing age which tends to increase SBP and PP during rest hypervolemic stress. The reduction in
BP obtained during rest HOWI in the YG group is in line with the previous study (33) measuring $\mathrm{BP}$ invasively during rest $\mathrm{HOWI}$ in young subjects.

Hunt et al. (20), and more recently Kornet et al. (34) suggested that assessment of variation in parameters derived from $\mathrm{CD}$ might serve as an appropriate index of arterial baroreceptor stimulus and resulting afferent activity. Recently, published papers, argue for an important role of arterial compliance in contributing to age-associated declines in baroreflex function $(9,35,36)$. The evaluation of carotid arterial compliance has also been reported to be an important tool for cardiovascular prognosis (including isolated systolic hypertension, left ventricular hypertrophy, congestive heart failure, and orthostatic and postprandial hypotension) in older adults (7,37-39). In the present study, the carotid arterial compliance was higher in YG subjects on basal conditions and consistently higher during rest hemodynamic stress. Furthermore, we demonstrated a positive correlation with carotid arterial compliance during basal conditions as well as under resting hypervolemic stress.

Since SBP changes are sensed by arterial baroreceptors located in the carotid sinus, the stiffening of this vessel might lead to less afferent firing for a given change in arterial pressure, which would reduce baroreceptor afferent responsiveness. Age-related vagal deficiencies may also reduce neural transduction of stretch into vagal outflow and blunt baroreflex responses. These structural and neural changes may contribute for SBRS differences between YG and OL groups, as well as BP deregulation during rest hypervolemic stress.

\section{Limitation of this study}

In the present study, all BP measurements were made in the periphery, which may not reflect changes that occur in the vascular regions of interest (i.e., carotid ar- 
tery). Furthermore, with advancing age, the amplification of the pressure wave between central and peripheral arteries is reduced so carotid and brachial SBP become similar in older adults (40). Another arterial BRS to control muscle sympathetic nerve activity and cardiopulmonary BRS were not analyzed.

The present study provides fundamental evidence that BP deregulation is prevalent in older adults during rest hemodynamic stress.
Age-related vagal dysfunction, as well as the elastic properties of the carotid artery, may contribute to SBRS differences between YG and OL groups, as well as BP elevation during rest central hypervolemia in healthy older men. Thus, the neural and structural adaptations appear to be components of fundamental importance for cardiovascular homeostasis during rest HOWI in healthy humans.

\section{References}

1. Wollner L \& Collins KJ (1992). Disorders of the autonomic nervous system. In: Brocklehurst JC, Tallis RC \& Fillit HM (Editors), Textbook of Geriatrics Medicine and Gerontology. 4th edn. Churchill Livingstone, Edinburgh, UK.

2. Ebert TJ, Morgan BJ, Barney JA, Denahan T \& Smith JJ (1992). Effects of aging on baroreflex regulation of sympathetic activity in humans. American Journal of Physiology, 263: H798-H803.

3. Shi X, Gallagher KM, Welch-O'Connor RM \& Foresman BH (1996). Arterial and cardiopulmonary baroreflexes in 60- to 69- vs 18- to 36year-old humans. Journal of Applied Physiology, 80: 1903-1910.

4. Epstein M (1992). Renal effects of head-out water immersion in humans: a 15-year update. Physiological Reviews, 72: 563-621.

5. Korner PI (1971). Integrative neural cardiovascular control. Physiological Reviews, 51: 312-367.

6. Shi X, Wray DW, Formes KJ, Wang HW, Hayes PM, O-Yurvati AH, Weiss MS \& Reese IP (2000). Orthostatic hypotension in aging humans. American Journal of Physiology, 279: H1548-H1554.

7. Tanaka H, Dinenno FA, Monahan KD, DeSouza CA \& Seals DR (2001). Carotid artery wall hypertrophy with age is related to local systolic blood pressure in healthy men. Arteriosclerosis, Thrombosis, and Vascular Biology, 21: 82-87.

8. Chapleau MW, Cunningham T, Sullivan MJ, Wachtel RE \& Abboud FM (1995). Structural versus functional modulation of the arterial baroreflex. Hypertension, 26: 341-347.

9. Monahan KD, Dinenno FA, Seals DR, Clevenger CM, DeSouza CA \& Tanaka $H$ (2001). Age-associated changes in cardiovagal baroreflex sensitivity are related to central arterial compliance. American Journal of Physiology, 281: H284-H289.

10. Monahan KD, Tanaka H, Dinenno FA \& Seals DR (2001). Central arterial compliance is associated with age- and habitual exerciserelated differences in cardiovagal baroreflex sensitivity. Circulation, 104: 1627-1632.

11. Lanne T \& Olsen H (1997). Decreased capacitance response with age in lower limbs of humans - a potential error in the study of cardiovascular reflexes in ageing. Acta Physiologica Scandinavica, 161: 503-507.

12. Olsen H, Vernersson E \& Lanne $T$ (2000). Cardiovascular response to acute hypovolemia in relation to age. Implications for orthostasis and hemorrhage. American Journal of Physiology, 278: H222-H232.

13. Ueno LM, Hamada T \& Moritani T (2002). Cardiac autonomic nervous activities and cardiorespiratory fitness in older men. Journal of Gerontology. Series A, Biological Sciences and Medical Sciences,
57: M605-M610

14. Ueno LM \& Moritani T (2003). Effects of long-term exercise training on cardiac autonomic nervous activities and baroreflex sensitivity. European Journal of Applied Physiology, 89: 109-114.

15. Sahn DJ, DeMaria A, Kisslo J \& Weyman A (1978). Recommendations regarding quantitation in M-mode echocardiography: results of a survey of echocardiographic measurements. Circulation, 58: 1072-1083.

16. Matsui T, Motohiko M, Hoshijima Y, Takahashi K, Yamamoto K, Yoshioka A \& Onodera S (2002). Effects of water immersion of systemic cardiovascular responses during recovery period following steady state land exercise. Tairyoku Kagaku, 51: 265-274.

17. Miyachi M, Donato AJ, Yamamoto K, Takahashi K, Gates PE, Moreau KL \& Tanaka H (2003). Greater age-related reductions in central arterial compliance in resistance-trained men. Hypertension, 41: 130-135.

18. Miyachi M, Kawano H, Sugawara J, Takahashi K, Hayashi K, Yamazaki K, Tabata I \& Tanaka H (2004). Unfavorable effects of resistance training on central arterial compliance. A randomized intervention study. Circulation, 110: 2858-2863.

19. Iellamo F, Legramante JM, Raimond G, Castrucci F, Massaro M \& Peruzzi G (1996). Evaluation of reproducibility of spontaneous baroreflex sensitivity at rest and during laboratory tests. Journal of Hypertension, 14: 1099-1104

20. Hunt BE, Fahy L, Farquhar WB \& Taylor JA (2001). Quantification of mechanical and neural components of vagal baroreflex in humans. Hypertension, 37: 1362-1368.

21. Mancia G, Parati G, Pomidossi G, Casadei R, Rienzo MD \& Zanchetti A (1986). Arterial baroreflexes and blood pressure and heart rate variabilities in humans. Hypertension, 8: 147-153.

22. Imai $Y$, Aihara A, Ohkubo T, Nagai K, Tsuji I, Minami N, Satoh H \& Hisamichi S (1997). Factors that affect blood pressure variability: a community-based study in Ohasama, Japan. American Journal of Hypertension, 10: 1281-1289.

23. Zito M, Parati G, Omboni S, Cervone C, Ulian L, D'Aviero M, Abate G \& Mancia G (1991). Effect of ageing on blood pressure variability. Journal of Hypertension, 9: S328-S329.

24. Miwa C, Sugiyama Y, Mano T, Matsukawa T, Iwase S, Watanabe T \& Kobayashi $F$ (2000). Effects of aging on cardiovascular responses gravity-related fluid shift in humans. Journal of Gerontology. Series A, Biological Sciences and Medical Sciences, 55: M329-M335.

25. Parati G, Grassi G, Coruzzi P, Musiari L, Ravogli A, Novarini A \& 
Mancia G (1987). Influence of cardiopulmonary receptors on the bradycardic responses to carotid baroreceptor stimulation in man. Clinical Sciences, 72: 639-645.

26. Shi X, Foresman BH \& Raven PB (1997). Interaction of central venous pressure, intramuscular pressure, and carotid baroreflex function. American Journal of Physiology, 272: H1359-H1363.

27. Potts JT, Shi X \& Raven PB (1995). Cardiopulmonary baroreceptors modulate carotid baroreflex control of the heart rate during dynamic exercise in humans. American Journal of Physiology, 268: H1567H1576.

28. Wiliamson JW, Michell JH, Olesen HL, Raven PB \& Secher NH (1994). Reflex increase in blood pressure induced by leg compression in man. Journal of Physiology, 475: 351-357.

29. Monahan KD, Dinenno FA, Seals DR \& Halliwill JR (2001). Smaller age-associated reductions in leg venous compliance in endurance exercise trained men. American Journal of Physiology, 281: H1267H1273.

30. Vaitkevicius PV, Fleg JL, Engel JH, O'Connor FC, Wright JG, Lakkata LE, Yin FC \& Lakkata EG (1993). Effects of age and aerobic capacity on arterial stiffness in healthy adults. Circulation, 88: 1456-1462.

31. Kober G \& Arndt JO (1970). Pressure-diameter relationship in the common carotid artery of the conscious man. Pflügers Archiv, 314: 27-39.

32. Angell-James JE \& Lumley JS (1975). Changes in the mechanical properties of the carotid sinus region and carotid sinus nerve activity in patients undergoing carotid endarterectomy. Journal of Physiology, 244: 80P-81P.

33. Gabrielsen A, Warberg J, Christensen NJ, Bie P, Stadeager C, Pump
B \& Norsk P (2000). Arterial pulse pressure and vasopressin release during graded water immersion in humans. American Journal of Physiology, 278: R1583-R1588.

34. Kornet L, Hoeks AP, Janssen BJ, Willigers JM \& Reneman RS (2002). Carotid diameter variations as a non-invasive tool to examine cardiac baroreceptor sensitivity. Journal of Hypertension, 20: 1165-1173.

35. Tanaka H, Dinenno FA, Monahan KD, Clevenger CM, DeSouza CA \& Seals DR (2000). Aging, habitual exercise, and dynamic arterial compliance. Circulation, 102: 1270-1275.

36. Hunt BE, Farquhar WB \& Taylor JA (2001). Does reduced vascular stiffening fully explain preserved cardiovagal baroreflex function in older, physically active men? Circulation, 103: 2424-2427.

37. Arnett DK, Evans GW \& Riley WA (1994). Arterial stiffness: a new cardiovascular risk factor? American Journal of Epidemiology, 140: 669-682.

38. Avolio AP, Deng FQ, Li WQ, Luo YF, Huang ZD, Xing LF \& O'Rourke MF (1985). Effects of aging on arterial distensibility in populations with high and low prevalence of hypertension: comparison between urban and rural communities in China. Circulation, 71: 202210.

39. Rowe JW (1987). Clinical consequences of age-related impairment in vascular compliance. American Journal of Cardiology, 60: 68G$71 \mathrm{G}$.

40. Nichols WW \& O'Rourke M (1998). McDonald's Blood Flow in Arteries. Theoretical, Experimental and Clinical Principles. 4th edn. Arnold E, London, England. 